\title{
Voltammetric Study of Uranyl-Selenium Interactions. Part 2. Uranyl(V) Selenate Complex
}

\author{
Marina Zelić,* Ivanka Pižeta, and Renata Djogić \\ Division for Marine and Environmental Research, Ruđer Bošković Institute, \\ P.O. Box 180, HR-10002 Zagreb, Croatia \\ RECEIVED JULY 14, 2011; REVISED NOVEMBER 16, 2012; ACCEPTED NOVEMBER 19, 2012
}

\begin{abstract}
Under the influence of recently published papers and some older own results, complex formation in uranyl(VI)-selenium(VI) system was reinvestigated at the ionic strengths of 0.1 and $3.0 \mathrm{~mol} \mathrm{~L}^{-1}$. Using electrolyzed selenate solutions (and square-wave voltammetry as a measuring technique) two coordination species at the higher electrolyte concentration $\left(\log \beta_{1}=1.48 \pm 0.01, \log \beta_{2}=2.4 \pm 0.1\right)$ were recognized, in agreement with the literature data based on other experimental methods. For successful interpretation of the voltammetric data, previously unknown weak complex $\left(\log \beta_{01}=0.7 \pm 0.1\right)$ of the reduction product, i.e. uranyl(V) should also be included in the model. At the lower electrolyte concentration $\left(0.1 \mathrm{~mol} \mathrm{~L}^{-1}\right)$, formation of complexes other than $\mathrm{UO}_{2} \mathrm{SeO}_{4}{ }^{0}$ cannot be unambiguously confirmed due to the narrow ligand concentration range.

Concerning the number of coordination species and their stability constants, seemingly different results that arise from voltammetry and other (independent) experimental methods reflect the fact that the former, in addition to the complexation of initially present metal ion, "sees" the coordination of its reduction product with the ligand of interest, too. When both processes are taken into account during treatment of voltammetric data, such differences disappear. (doi: 10.5562/cca1952)
\end{abstract}

Keywords: uranyl, selenate, square wave voltammetry, complex formation, stability constants

\section{INTRODUCTION}

Complexation of uranyl(VI) ions with selenium containing ligands was virtually unknown. ${ }^{1,2}$ until Lubal and $\mathrm{Havel}^{3}$ published experimental results on the formation of $\mathrm{UO}_{2}\left(\mathrm{SeO}_{4}\right)_{n}{ }^{(2 n-2)-}$ coordination species. From spectrophotometric measurements, at the ionic strength of $3 \mathrm{~mol} \mathrm{~L}^{-1}$, two stability constants $\left(\log \beta_{1}=\right.$ $\left.1.57 \pm 0.01, \log \beta_{2}=2.42 \pm 0.01\right)$ arose. At infinite dilution, the situation was more ambigous $\left(\log \beta_{1}=\right.$ $2.64 \pm 0.01, \log \beta_{2} \leq 3.4$ - based on potentiometric titration). Under the influence of such conclusions and some other unexplained effects, we performed a similar study ${ }^{4}$ by means of square-wave voltammetry $(\mathrm{SWV})^{5}$ that included not only uranyl(VI)-selenate, but also uranyl(VI)-selenite interactions. Final results were only partly in agreement with the above mentioned values, because $\log \beta_{1}=1.57 \pm 0.01$ was obtained again (at $I=3 \mathrm{~mol} \mathrm{~L}^{-1}$ ) but formation of the higher coordination species with $\beta_{2}>\beta_{1}$ could not be confirmed although measurements in highly concentrated ligand solutions were included.
The study of uranyl(VI)-selenite (i.e. selenium(IV)) interactions was complicated by electroactivity of the ligand and overlapping of its first voltammetric signal with reduction peak of uranyl(VI). Consequently, our previous study yielded inconclusive results concerning the possible complex formation.

In subsequent articles, the complexation of $\mathrm{UO}_{2}{ }^{2+}$ with selenium(VI) or selenium(IV) was described by other experimental techniques such as time-resolved laser-induced fluorescence spectroscopy ${ }^{6}$ and capillary electrophoresis ${ }^{7}$. Two uranyl(VI) complexes with selenium(VI) (i.e. selenate) and one or two coordination species with selenium(IV) seem to be confirmed. The reasons that prevent obtaining of similar voltammetric results in the former case stay unclear whereas in the latter they are more or less obvious. In this article, the origin of such discrepancy and its elimination are described. Deeper insight into uranyl-selenium interactions could be important for understanding of some toxic effects ${ }^{8}$ and preparation of materials with very specific properties ${ }^{9}$.

\footnotetext{
* Author to whom correspondence should be addressed. (E-mail: zelic@irb.hr)
} 


\section{EXPERIMENTAL}

All solutions of $\mathrm{NaClO}_{4}, \mathrm{Na}_{2} \mathrm{SeO}_{4}$ and $\mathrm{HClO}_{4}$ were prepared by dissolution of reagent grade chemicals, produced by Merck, Fluka and Kemika (Zagreb) in doubly distilled water. For preparation of dissolved uranyl(VI), a classical procedure from Gmelins handbook $^{10}$ was applied.

SWV measurements were performed using PAR 303A static mercury drop electrode connected to the Autolab System (Eco Chemie, Utrecht). Platinum wire served as a counter electrode whereas all potentials were defined with respect to the saturated $\mathrm{Ag} \mid \mathrm{AgCl}(\mathrm{NaCl})$ reference electrode. High purity nitrogen was used for deaeration of the measuring solution.

All experiments were performed at $23 \pm 2{ }^{\circ} \mathrm{C}$.

In the first part of each experiment, uranyl(VI) reduction signal was followed at increasing selenate level, starting from the metal solution in $3 \mathrm{~mol} \mathrm{~L}^{-1}$ $\mathrm{NaClO}_{4}$ to which $1 \mathrm{~mol} \mathrm{~L}^{-1}$ ligand solution was gradually added at a constant level of dissolved metal (0.1 mmol L $\left.{ }^{-1}\right)$ and constant acidity $(\mathrm{pH}=3)$. After the selenate concentration in the polarographic cell reached the value of $0.5 \mathrm{~mol} \mathrm{~L}^{-1}$, the second part of the experiment started in which $1 \mathrm{~mol} \mathrm{~L}^{-1}$ selenate solution was titrated with $3 \mathrm{~mol} \mathrm{~L}^{-1}$ sodium perchlorate. Such an experimental protocol yielded the widest possible ligand concentration range. The same approach was applied at the lower ionic strength $\left(0.1 \mathrm{~mol} \mathrm{~L}^{-1}\right)$ with perchlorate and selenate concentrations of 0.1 and $0.033 \mathrm{~mol} \mathrm{~L}^{-1}$, respectively.

\section{Data Treatment}

In voltammetry, characterization of kinetically labile metal complexes $\left(\mathrm{ML}_{\mathrm{j}}\right)$, i.e. determination of their stability constants is usually based on following the shift of reduction signal with increasing ligand concentration at a constant (dissolved) metal concentration and fixed ionic strength ${ }^{11,12}$. Such a procedure has its origin in the Nernst equation, i.e. change of the concentration ratio between oxidized and reduced forms of the studied redox pair. When an amalgam forming metal appears as a product of the electrode reaction, only free metal ion is of interest. The titration procedure in such a case is described by the following equation:

$$
\begin{aligned}
\Delta E_{\mathrm{p}}= & 2.303(R T / n F) \times \log \left(1+\beta_{1}[\mathrm{~L}]+\right. \\
& \left.\beta_{2}[\mathrm{~L}]^{2}+\beta_{3}[\mathrm{~L}]^{3}+\ldots \beta_{N}[\mathrm{~L}]^{N}\right)
\end{aligned}
$$

where $\Delta E_{\mathrm{p}}$ denotes the peak potential shift, i.e. the difference between peak potentials in the absence and presence of the complex forming agent, $\mathrm{n}$ is the number of exchanged electrons in the electrode reaction and $\beta_{j}$ is the cumulative stability constant:

$$
\beta_{j}=\left[\mathrm{ML}_{j}\right] /[\mathrm{M}][\mathrm{L}]^{j}
$$

Other symbols $(R, T, F)$ have their usual meanings, whereas $N$ denotes the number of ligands bound in the highest complex species.

When the electrode process "produces" the ion of lower charge (instead of metal atom), two possibilities exist; either the dissolved product stays "free" or it becomes coordinated with the ligand of interest. In the first case, gradual increase of the total ligand concentration causes the absolute concentration of the free oxidized metal ion to decrease, but its ratio to the free reduced form is not affected. Under such conditions, equation (1) is applicable again. When the metal ion of lower charge is coordinated, the equation:

$$
\begin{aligned}
& \Delta E_{\mathrm{p}}=2.303(R T / n F) \times \\
& \log \frac{1+\beta_{1}[\mathrm{~L}]+\beta_{2}[\mathrm{~L}]^{2}+\beta_{3}[\mathrm{~L}]^{3}+\ldots \beta_{N}[\mathrm{~L}]^{N}}{1+\beta_{01}[\mathrm{~L}]+\beta_{02}[\mathrm{~L}]^{2}+\beta_{03}[\mathrm{~L}]^{3}+\ldots \beta_{0 N}[\mathrm{~L}]^{0 N}}
\end{aligned}
$$

should be used instead. Here $\beta_{0 j}$ denotes cumulative constant of the corresponding complex that contains reduced metal ion and the ligand of interest. In both cases, constant height of the reduction signal is assumed. Otherwise, additional correction is needed. ${ }^{12}$

\section{RESULTS AND DISCUSSION}

Taking into account that during preparation of our previous article ${ }^{4}$ complexation of uranium(V) (i.e. of urani$\mathrm{um}(\mathrm{VI})$ reduction product ${ }^{13}$ ) was generally treated as an exception, experimental results from the study of $\mathrm{UO}_{2}{ }^{2+}-\mathrm{SeO}_{4}{ }^{2-}$ interactions were originally described by means of equation (1). Under such conditions (at the ionic strength of $3 \mathrm{~mol} \mathrm{~L}^{-1}$ ) only $\mathrm{UO}_{2} \mathrm{SeO}_{4}{ }^{0}$ seems to be formed up to the ligand concentration of $1 \mathrm{~mol} \mathrm{~L}^{-1}$. Therefore, the peak potential shift is generally lower than expected for the published values of stability constants $^{3}$. The difference becomes more pronounced as the ligand concentration increases and finally reaches the value of $47 \mathrm{mV}$ in $1 \mathrm{~mol} \mathrm{~L}^{-1}$ selenate solution (Figure 1).

The mentioned conclusion about the maximum coordination number also arises from the highest slope (59 $\mathrm{mV}$ per decade unit) of $\Delta E_{\mathrm{p}} v s . \log \left[\mathrm{SeO}_{4}{ }^{2-}\right]$ curve.

During the last decade an increasing interest in complex formation of uranyl(V) could be observed. ${ }^{14-21}$ According to the resulting conclusions, both $\mathrm{UO}_{2}{ }^{2+}$ and $\mathrm{UO}_{2}{ }^{+}$can often be coordinated by the same type of ligand but in the latter case stability constants are lower. Therefore such a possibility should be taken into account when voltammetric data from uranyl(VI)-selenate 


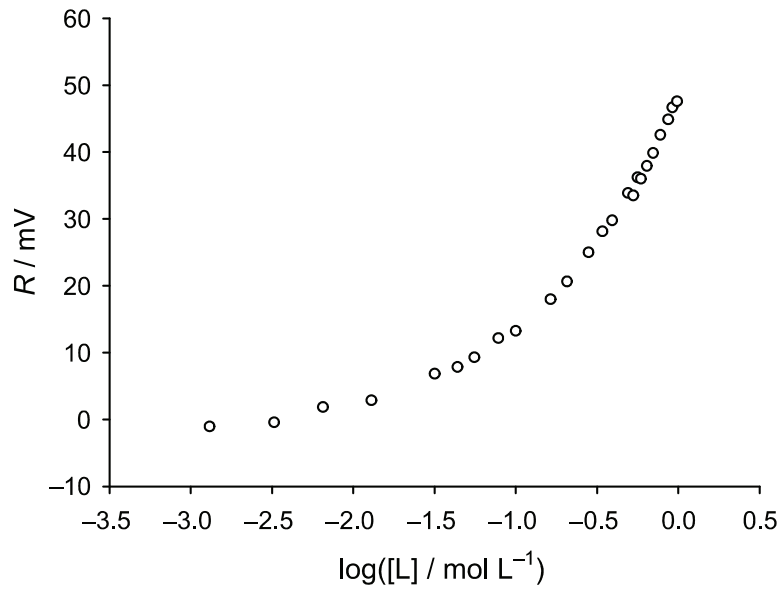

Figure 1. The difference between peak potential shift, expected according to the published stability constants and its experimentally obtained value as a function of selenate concentration in $\mathrm{UO}_{2}{ }^{2+}-\mathrm{SeO}_{4}{ }^{2-}$ system. Uranyl(VI) concentration: $0.1 \mathrm{mmol} \mathrm{L}{ }^{-1}, \mathrm{pH}=3$, ionic strength: $3 \mathrm{~mol} \mathrm{~L}^{-1}$ maintained with $\mathrm{NaClO}_{4}$, SW frequency: $100 \mathrm{~s}^{-1}$, amplitude: $50 \mathrm{mV}$, step potential: $2 \mathrm{mV}$.

system are treated. The results of this type, obtained by equation (3) instead of equation (1), are given in Figure 2. Their best description is achieved when two coordination species of uranyl(VI) and one complex of uranyl(V) are assumed $\left(\log \beta_{1}=1.48 \pm 0.01, \log \beta_{2}=2.4 \pm 0.1\right.$, $\left.\log \beta_{01}=0.7 \pm 0.1\right)$. In other words, a weak species $\mathrm{UO}_{2} \mathrm{SeO}_{4}^{-}$seems to exist. However, it can be "seen" only when previously electrolyzed selenate solution ${ }^{4}$ is used. Otherwise, results are obviously affected by the selenite that always appears as an impurity in such systems. Its direct interaction with the metal ions is most

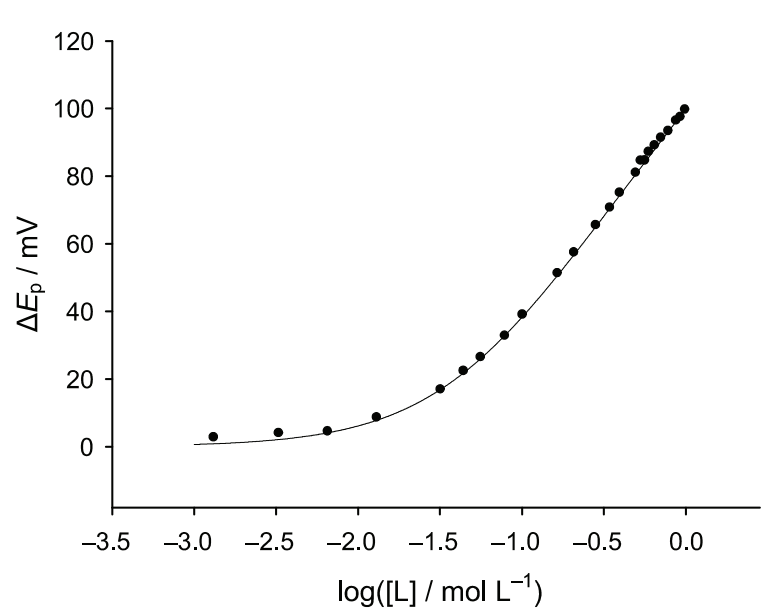

Figure 2. Peak potential shift as a function of selenate concentration. Experimental conditions given in description of Figure 1. Solid line obtained by fitting of the experimental points with equation (3), i.e. assuming complexation of $\mathrm{UO}_{2}{ }^{2+}$ and its reduction product $\mathrm{UO}_{2}{ }^{+}$, too.

probably not very important at such low concentrations, but its electroactivity which results in modified electrode surface ${ }^{22}$ and overlapping of its first reduction peak with uranyl(VI) signal could be of interest.

The mentioned result is important for at least two reasons. First, it demonstrates that even weak complexation of the reduction product with the ligand of interest could significantly influence the experimental results (i.e. final conclusions). Second, it points to the previously unknown coordination of uranyl(+5) with selenate.

All stability constants (literature and own) of uranyl ions with selenium containing (inorganic) ligands are given in Table 1.

Table 1. Stability constants of $\mathrm{UO}_{2}{ }^{2+}$ and $\mathrm{UO}_{2}{ }^{+}$complexes with selenate and selenite

\begin{tabular}{|c|c|c|c|c|c|c|}
\hline Cation & Anion & $\log \beta_{1}$ & $\log \beta_{2}$ & $I / \mathrm{mol} \mathrm{L}^{-1}$ & Method $^{(\mathfrak{b})}$ & Ref. $^{(b)}$ \\
\hline \multirow[t]{6}{*}{$\mathrm{UO}_{2}^{2+}$} & $\mathrm{SeO}_{4}^{2-}$ & $1.57 \pm 0.01$ & $2.42 \pm 0.01$ & 3 & spectroph. & 3 \\
\hline & & $2.64 \pm 0.01$ & $\leq 3.4$ & 0 & pot. & 3 \\
\hline & & $1.57 \pm 0.01$ & & 3 & SWV & 4 \\
\hline & & $2.0 \pm 0.1$ & & 0.1 & SWV & 4 \\
\hline & & $2.93 \pm 0.06$ & $4.03 \pm 0.18$ & 0 & $\mathrm{CE}$ & 7 \\
\hline & & $1.48 \pm 0.01$ & $2.4 \pm 0.1$ & 3 & SWV & t.w. \\
\hline \multirow[t]{5}{*}{$\mathrm{UO}_{2}^{2+}$} & $\mathrm{HSeO}_{3}^{-}$ & $3.35 \pm 0.12$ & & 0.05 & TRLFS & 6 \\
\hline & & $3.32 \pm 0.15$ & & 0.2 & TRLFS & 6 \\
\hline & & $3.37 \pm 0.17$ & & 0.035 & spectroph. & 6 \\
\hline & & $3.62 \pm 0.15^{(a)}$ & & 0 & spectroph. & 6 \\
\hline & & $3.37 \pm 0.15$ & $5.51 \pm 0.11$ & 0 & $\mathrm{CE}$ & 7 \\
\hline $\mathrm{UO}_{2}^{+}$ & $\mathrm{SeO}_{4}^{2-}$ & $0.7 \pm 0.1$ & & 3 & SWV & t.w. \\
\hline
\end{tabular}

\footnotetext{
(a) at $20^{\circ} \mathrm{C}$

${ }^{(b)}$ spectroph. $=$ spectrophotometry, pot. = potentiometry, SWV $=$ square wave voltammetry, $\mathrm{CE}=$ capillary electrophoresis,
} TRLFS $=$ time-resolved laser-induced fluorescence spectroscopy, t.w. $=$ this work 


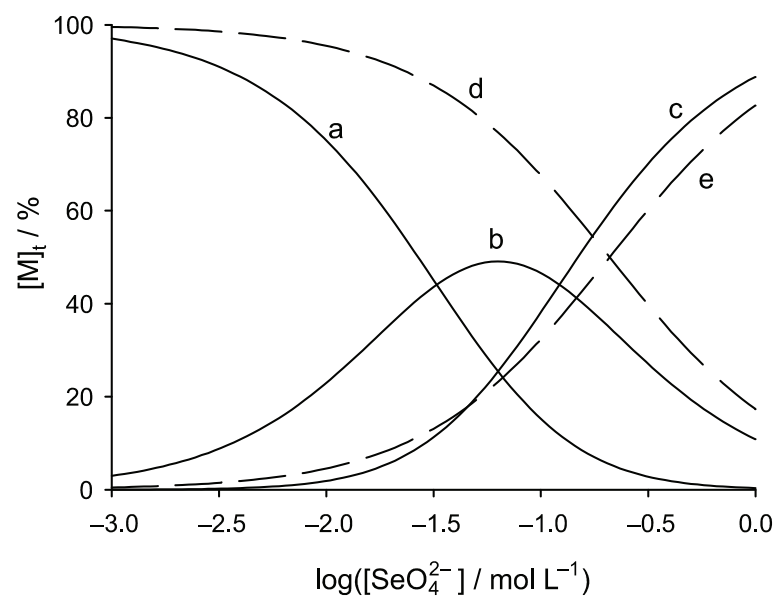

Figure 3. Distribution of the total dissolved uranyl(VI) (一) among $\mathrm{UO}_{2}{ }^{2+}$ (a), $\mathrm{UO}_{2} \mathrm{SeO}_{4}{ }^{0}$ (b) and $\mathrm{UO}_{2}\left(\mathrm{SeO}_{4}\right)_{2}{ }^{2-}$ (c), and uranyl(V) (-- - ) among $\mathrm{UO}_{2}^{+}(\mathrm{d})$ and $\mathrm{UO}_{2} \mathrm{SeO}_{4}^{-}$(e) in dependence on the ligand concentration. Calculations based on stability constants from this work.

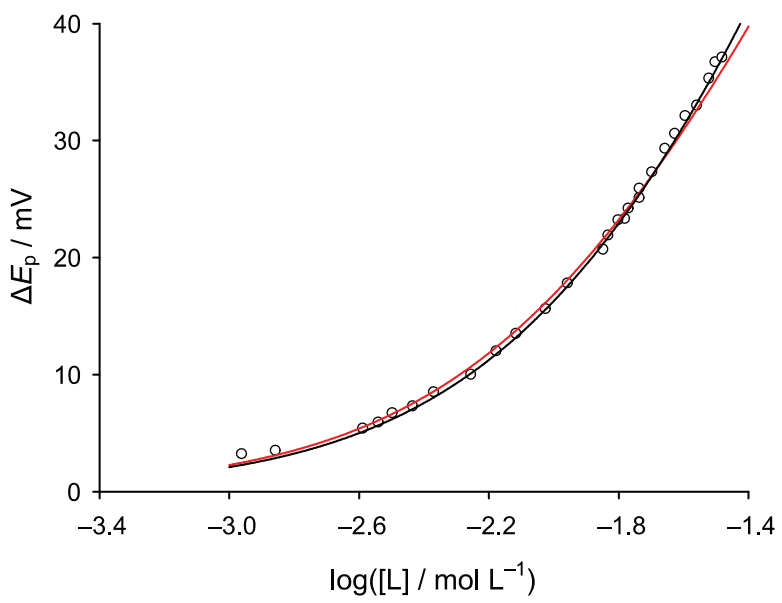

Figure 4. Peak potential shift in dependence on the ligand concentration at the ionic strength of $0.1 \mathrm{~mol} \mathrm{~L}^{-1}$. Other conditions given in description of Figure 1. Experimental points fitted assuming formation of $\mathrm{UO}_{2} \mathrm{SeO}_{4}{ }^{0}$ (-) or $\mathrm{UO}_{2} \mathrm{SeO}_{4}{ }^{0}$ and $\mathrm{UO}_{2}\left(\mathrm{SeO}_{4}\right)_{2}{ }^{2-}$ complex species (一).

The already mentioned slope of $\Delta E_{\mathrm{p}} v s . \log \left[\mathrm{SeO}_{4}{ }^{2-}\right]$ linear segment (59 $\mathrm{mV}$ per decade unit) is not in contradiction to the present model. The reason is that in concentrated ligand solutions uranium(VI) mainly exists as $\mathrm{UO}_{2}\left(\mathrm{SeO}_{4}\right)_{2}{ }^{2-}$ whereas uranium(V) is in the form of $\mathrm{UO}_{2} \mathrm{SeO}_{4}^{-}$(Figure 3). Under such conditions $\Delta E_{\mathrm{p}}$ is a linear function of $\log \left(\left[\mathrm{SeO}_{4}{ }^{2-}\right]^{2} /\left[\mathrm{SeO}_{4}{ }^{2-}\right]\right)$, i.e. of $\log$ $\left[\mathrm{SeO}_{4}{ }^{2-}\right]$, according to equation 3 . In other words, its slope is $59 \mathrm{mV} /$ d.u. and not $2 \times 59 \mathrm{mV} /$ d.u. although the highest complex is of $\mathrm{ML}_{2}$ type.

It should be emphasized that the selenate complex of uranyl(V) cannot be characterized at low ionic strengths (such as $0.1 \mathrm{~mol} \mathrm{~L}^{-1}$ ) because it is a minor species within the accessible ligand concentration range (up to $0.033 \mathrm{~mol} \mathrm{~L}^{-1}$ ). In this case, the peak shift as a function of selenate concentration (Figure 4) can be described with equation (1) and the model that includes one $\left(\log \beta_{1}=1.97 \pm 0.01\right)$ or two complex species $\left(\log \beta_{1}=1.93 \pm 0.01, \log \beta_{2}=2.60 \pm 0.07\right)$. The latter seems better as follows from the visual inspection of curve fitting or statistical treatment of experimental values. However, the differences between these two possibilities are not (significantly) higher than the experimental error.

In order to verify this result, we compared our conclusions with those that arise from the study of uranyl(VI) complexation with a similar ligand (i.e. sulfate) by an independent method. ${ }^{23}$ The latter results indicate formation of two complexes at the ionic strength of $0.1 \mathrm{~mol} \mathrm{~L}^{-1}$. The problem is, however, that at the higher electrolyte concentration three (sulfate) complexes seem to appear, in disagreement with all known results on the uranyl(VI) coordination with selenate ion. In the mentioned study the ionic strength was defined through the constant concentration of sodium ions leading to somewhat different experimental results based on significantly wider ligand concentration range (i.e. higher maximum ligand level).

Therefore, clear insight into uranyl-selenate interactions at the low ionic strength is still lacking.

At both electrolyte concentrations, it is important to perform voltammetric measurements with chemicals of high purity (especially with respect to the presence of selenite) and small step potentials in order to obtain accurate readings of $E_{\mathrm{p}}$ values. (The latter can be improved by additional signal processing.) The main problem with nonelectrolyzed selenate solutions is the dispersion of experimental points that prevents recognition of the weak $\mathrm{UO}_{2} \mathrm{SeO}_{4}{ }^{-}$or any other minor species in a curve fitting procedure.

It follows from equation (3) that the difference $(R)$ between the peak potential shift, expected from the stability constants determined by some other measuring technique and its experimental value (Figure 1) reflects complexation of reduced form of the dissolved metal, i.e.

$$
\begin{aligned}
& R=2.303(R T / n F) \times \\
& \log \left(1+\beta_{01}[\mathrm{~L}]+\beta_{02}[\mathrm{~L}]^{2}+\beta_{03}[\mathrm{~L}]^{3}+\ldots \beta_{0 N}[\mathrm{~L}]^{0 N}\right)
\end{aligned}
$$

When different experimental techniques give similar results (concerning the number of possible coordination species and their stability constants) but voltammetric peak potential shifts are significantly lower than expected on the basis of such results, possible complex formation of the reduction product with the ligand of interest should always be taken into consideration. From such results the constants of interest can be calculated without difficulties, because equation (4) is in 


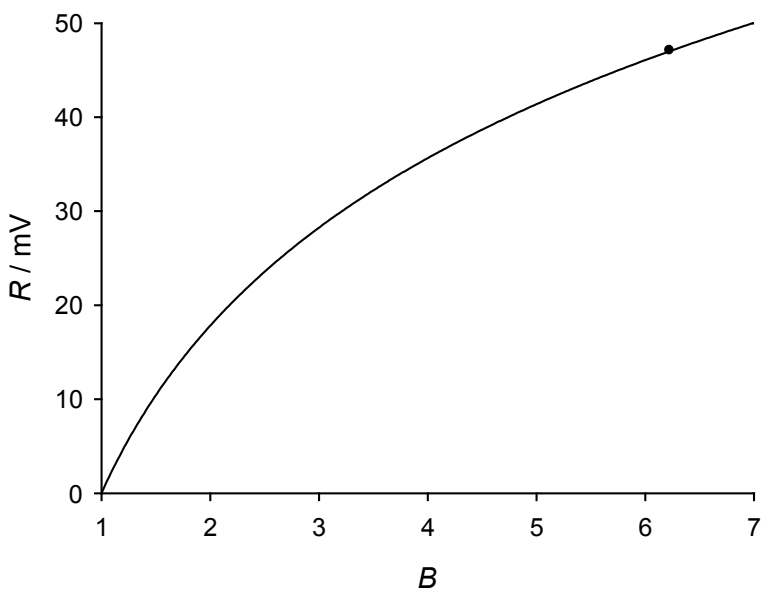

Figure 5. The difference between peak potential shift, that reflects complexation of the oxidized form of dissolved metal, and its experimentally obtained value in dependence on $B$, i.e. denominator of equation (3) when one electron is exchanged in the electrode process. The last point from Figure 1 included.

fact equation (1) applied to the reduced metal ion (but with $R$ introduced instead of classical $\Delta E_{\mathrm{p}}$ ). Additionally, $R$ value can be correlated with the value within parentheses in equation (4), i.e. with denominator in equation (3). The resulting graphical presentation, assuming single electron reduction, is given in Figure 5.

In practice, it could be useful for direct reading of $1+\beta_{01}[\mathrm{~L}]+\beta_{02}[\mathrm{~L}]^{2}+\beta_{03}[\mathrm{~L}]^{3}+\ldots \beta_{0 N}[\mathrm{~L}]^{N}$ when experimentally obtained $R$ value is known. Obviously, the conditions for (successful) voltammetric characterization of kinetically labile complexes (concerning reversibility of the reduction process, absence of ligand or complex adsorption etc.) should be fulfilled in the whole ligand concentration range. $R$ values, significantly higher than the experimental error, that show the trend given in Figure 1 are also needed.

Going back to the initially defined question about the origin of different results that arise from voltammetry and other experimental techniques, application of an inappropriate voltammetric data treatment which cannot give satisfactory constants (even when based on measurements with purified selenate solutions) should be recognized. More precisely, the problem arises because voltammetry "sees" not only the complexes of uranyl(VI) but also of its reduction product, i.e. uranyl(V). When the latter process is taken into account the mentioned differences disappear.

\section{CONCLUSION}

Voltammerically determined stability constants in $\mathrm{UO}_{2}{ }^{2+}-\mathrm{SeO}_{4}{ }^{2-}$ system (at the ionic strength of $3 \mathrm{~mol} \mathrm{~L}^{-1}$ ) are nearly the same as those that arise from other experimental methods, only if the previously electrolyzed ligand (stock) solution is applied and the measured data is treated according to the model which includes complexation of the reduction product, i.e. $\mathrm{UO}_{2}{ }^{+}$. Although many coordination species of so called pentavalent uranium with different ligands were described during the last decade this is the first indication of $\mathrm{UO}_{2} \mathrm{SeO}_{4}^{-}$formation.

At the lower ionic strength $\left(0.1 \mathrm{~mol} \mathrm{~L}^{-1}\right)$ the situation is not so simple because of the narrow accessible ligand concentration range (up to $0.033 \mathrm{~mol} \mathrm{~L}^{-1}$ ). Under such conditions other possible complexes, in addition to $\mathrm{UO}_{2} \mathrm{SeO}_{4}{ }^{0}$, cannot be confirmed unambiguously. If they exist, their relative concentrations (and therefore "contributions" to the peak potential shift) are very low.

Seemingly different results that arise from voltammetry and other (independent) methods reflect the fact that the former, in addition to the complexation of initially present metal ion, detects the coordination of its reduction product with the ligand of interest. When the latter process is taken into account during treatment of voltammetric data, such differences disappear.

Acknowledgements. Financial support of the Ministry of Science, Education and Sport of Croatia, within the projects Investigations of Microcrystals and Traces of Dissolved Compounds, and Interactions of Trace Metals in Aquatic Environment is gratefully acknowledged.

\section{REFERENCES}

1. NIST Critically Selected Stability Constants of Metal Complexes Database, Version 5.0. Gaithersburg 1998.

2. F. Séby, M. Potin-Gautier, E. Giffaut, G. Borge, O. F. X. Donard, Chem. Geol. 171 (2001) 173-194.

3. P. Lubal, J. Havel, Talanta 44 (1997) 457-466.

4. R. Djogić, I. Pižeta, M. Zelić, Anal. Chim. Acta 404 (2000) 159166.

5. V. Mirčeski, Š. Komorsky-Lovrić, M. Lovrić, Square-Wave Voltammetry, Springer, Berlin 2007.

6. V. Sladkov, B. Fourest, F. Mercier, Dalton Trans. 2009, 7734 7740 .

7. V. Sladkov, Electrophoresis 31 (2010) 3482-3491.

8. M. Czauderna, E. Makowska, S. Smolinski, J. Radioanal. Nucl. Chem. 177 (1994) 393-401.

9. S. V. Krivovichev, V. Kahlenberg, I. G. Tananaev, R. Kaindl, E. Mersdorf, B. F. Myasoedov, J. Am. Chem. Soc. 127 (2005) 1072-1073.

10. Gmelins Handbuch det anorganischen Chemie, No. 55, $8^{\text {th }}$ ed., Verlag Chemie, Weinheim 1936, p.136.

11. D. D. DeFord and D. N. Hume, J. Am. Chem. Soc. 73 (1951) 5321-5322.

12. D. R. Crow, Polarography of Metal Complexes, Academic Press, London 1969.

13. T. R. Mueller, M. Petek in A. J. Bard (ed.) Encyclopedia of Electrochemistry of the Elements, Vol. IX, Part. B, Dekker, New York, 1986. pp. 439-665.

14. D. E. Morris, Inorg. Chem. 41 (2002) 3542-3547.

15. K. Mizouka, I. Grenthe, Y. Ikeda, Inorg. Chem. 44 (2005) 4472 4474 . 
16. K. Mizouka, S. Tsushima, M. Hasegawa, T. Hoshi, Y. Ikeda, Inorg. Chem. 44 (2005) 6211-6218.

17. Z. Szabó, T. Toraishi, V. Vallet, I. Grenthe, Coord. Chem. Rev. 250 (2006) 784-815.

18. A. Ikeda, K. Henning, S. Tsushima, K. Takao, Y. Ikeda, A. C. Scheinost, G. Bernhard, Inorg. Chem. 46 (2007) 4212-4219.

19. G. R. Graves, B. L. Scott, D. E. Morris, J. L. Kiplinger, Chem. Commun. 2009, 776-778.
20. P. L. Arnold, J. B. Love, D. Patel, Coord. Chem. Rev. 253 (2009) 1973-1978.

21. C. R. Graves, J. L. Kiplinger, Chem. Commun. 2009, 38313853.

22. M. Zelić, L. Sipos, M. Branica, Croat. Chem. Acta 58 (1985) 4355.

23. T. Vercouter, P. Vitorge, B. Amekraz, C. Moulin, Inorg. Chem. 47 (2008) 2180-2189. 